\title{
Thermogravimetric analysis and carbon stability of chars produced from slow pyrolysis and hydrothermal carbonization of manure waste
}

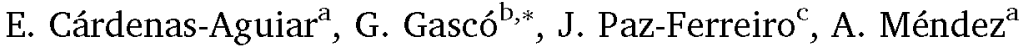 \\ a Departamento de Ingeniería Geológica y Minera, ETSI Minas y Energía, Universidad Politécnica de Madrid, C/Ríos Rosas 21, 28003 Madrid, Spain

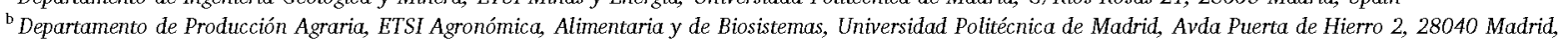 \\ Spain \\ ${ }^{c}$ School of Engineering, RMT University, GPO Box 2476, 3001 Melbourne, VIC, Australia
}

\begin{abstract}
A B S T R A G T
Large amounts of manure waste are produced worldwide. Land application of manure waste is the most common approach to valorization. This practice has several environmental concerns, including pathogen spreading, emissions of odorous chemicals (ammonia or methane) and the pollution of waterbodies with nitrogen and phosphorous compounds. The pyrolysis of manure for biochar production has been tested as a useful treatment to avoid these concerns but the high moisture of some wastes hinders its thermo-chemical valorisation in the absence of a pre-drying step. Recently, hydrothermal carbonization (HTC) of wet biomass has been identified as a cost-effective valorisation method of biomass without the need for energy-intensive drying processes. The objective of this study is to compare the properties of pyrochars and hydrochars prepared from thermal treatment of rabbit manure (MW). Pyrochars were prepared at $450{ }^{\circ} \mathrm{C}$ (BMW450) and $600{ }^{\circ} \mathrm{C}(\mathrm{BMW600})$ and hydrochars were obtained using a rabbit manure solution (solid:water ratio $30: 70$ ) that was heated at $190^{\circ} \mathrm{C}$ (HMW190) and $240^{\circ} \mathrm{C}$ (HMW240). The final temperature was maintained during $1 \mathrm{~h}$ for pyrochars and $6 \mathrm{~h}$ for hydrochars. Results showed that HTC generated more micro-, meso- and macro-porosity than pyrolysis. Pyrochar produced at $600^{\circ} \mathrm{C}$ possessed a high thermal, chemical and biological stability, probably due to its highly aromatic structure. Hydrochars (HMW190 and HMW240) were predominantly aliphatic, and this was associated to a lower chemical and thermal stability than pyrochars. The germination index values indicated that the pyrochar BMW450 and the two hydrochars were highly phytotoxic while pyrochar MWB600 presented a moderate phytotoxicity, which was lower than the manure waste. Finally, $\mathrm{CO}_{2}$ emissions of different materials after 60 days followed the order: MW > HMW190 > HMW240 > BMW450 > BMW600. Specifically, pyrolysis evolved $\mathrm{CO}_{2}$ was reduced between $97.8-88.7 \%$ with respect to raw material after pyrolysis. The HTC treatment diminished evolved $\mathrm{CO}_{2}$ between $68.8-59.0 \%$, with respect to the manure. These results indicate that both processes can be considered as carbon fixation technologies.
\end{abstract}

\section{Introduction}

Large amounts of manure waste are produced worldwide, with 1.4 billion tonnes produced in the European Union [1]. Some organic wastes can be applied untreated to the land. However, the disposal of this waste can be associated with environmental concerns if a stabilization process is not followed.

In Mediterranean areas, soils are prone to degradation. The climate of the area results in soils with a relatively low organic matter content. Industrial agriculture is prevalent in these areas. Land application of organic residues, including animal manures, is a management strategy, which could reverse soil organic matter depletion, while contributing to alleviate the environmental concerns associated to other types of disposal. Traditionally, manure wastes have been used as soil amendments in the areas surrounding its source. However, the change in livestock farming towards high-density animal feeding operations years has resulted in manure productions far exceeding local soil demands. In addition, direct manure waste application to soil can spread pathogens, emit ammonia, methane and other odorous chemicals, while polluting surface and groundwater with nitrogen and phosphorous compounds, leading to water eutrophication [2].

Efforts to close nutrient cycling at the farm scale, by improving the use of nutrients could effectively reduce the above-mentioned environmental burdens. A reasonable body of literature on valorization, 
aimed towards soil amendment of animal manures in Mediterranean areas using composting and vermi-composting is available $[3,4]$. However, the properties of the finished composts, including $\mathrm{pH}$ and electrical conductivity might limit the use of these products in agriculture [5].

These environmental threats are calling for new environmental management approaches. Relatively few research transforming manure into alternative products to composts is available to date. Thermochemical treatments could be an interesting management practice for manure wastes. Among thermochemical conversion processes, pyrolysis and hydrothermal carbonization of several organic waste streams have gathered increasing interest in recent years [6,7]. During pyrolysis, the organic matter is thermochemically transformed at temperatures between 300 and $700{ }^{\circ} \mathrm{C}$ in the absence or with limited oxygen. For hydrothermal carbonization (HTC), the organic matter is treated at temperatures between 180 and $240{ }^{\circ} \mathrm{C}$, in the presence of water and under autogenous pressure. The main advantage of HTC resides in its ability to convert wet biomass, without the need for the high energy intensive drying process, pre- or during pyrolysis. HTC or pyrolysis lead to chars with high carbon content, in addition with liquid and gaseous fractions $[8,9]$. The properties of the chars could vary drastically depending on the thermochemical process and experimental conditions used, mainly heating rate, final temperature or time of reaction [10-12]. In general, temperature is considered to exert a greater influence in the quality and properties of the final char, and most research has been focused on this topic $[10,13]$.

When the char produced from pyrolysis is used as soil amendment is termed pyrochar, whereas char produced from HTC is named hydrochar. The composition, structure and potential uses of pyrochars and hydrochars could vary depending on the process conditions and feedstock composition. Traditionally, pyrochars produced at higher temperatures show a greater stability and can be used for carbon sequestration whereas pyrochars obtained at lower temperatures and from feedstocks with high nutrient contents like manure wastes or sewage sludges show favorable properties as amendments, with the potential to replace commercial fertilizers $[14,15]$. Hydrochars have been far less studied than pyrochars. In general, it has been found that the $\mathrm{pH}$ of hydrochars and pyrochars differ, with the latter being in general more alkaline [16], though exceptions may occur [14]. Hydrochars also tend to exhibit higher $\mathrm{H} / \mathrm{C}$ and $\mathrm{O} / \mathrm{C}$ ratios than pyrochars [17]. Some authors have reported phytotoxicity and low stability in hydrochars $[18,19]$, while fewer concerns exist in regards to the phytotoxicity of pyrochars [20]. The nutrient content and other relevant properties for soil addition purposes are going to vary depending on the choice of thermochemical process and the temperature of operation.

A characterization of pyrochars and hydrochars prepared at different temperatures is a valuable knowledge to inform future technoeconomic assessment which could evaluate the potential trade-offs of both technologies. Thus, the aim of this work is to explore the impact of temperature on the agronomic properties of chars prepared from manure waste and using two technologies, slow pyrolysis and hydrothermal carbonization. A focus of this study is the stability of the chars and the study of their potential phytotoxicity.

\section{Materials and methods}

\subsection{Raw material selection and char preparation}

The manure waste (MW) was obtained from a rabbit farm located in the practice field of Universidad Politécnica de Madrid. Two pyrochars and two hydrochars were prepared using MW as raw material.

The two pyrochars were prepared as follows: $500 \mathrm{~g}$ of air dried MW were introduced in a $2 \mathrm{~L}$ steel reactor supplied by Demede S.L. Samples were heated at $3^{\circ} \mathrm{C} \mathrm{min}{ }^{-1}$ until 450 and $600{ }^{\circ} \mathrm{C}$ leading to BMW450 and BMW600, respectively. The final temperature was maintained for $1 \mathrm{~h}$ using a $\mathrm{N}_{2}$ flow of $0.5 \mathrm{~L} \mathrm{~min}^{-1}$. The steel reactor has two thermocouples, one is inserted into the recipient in contact with the sample and another one is in contact with the external part of the steel wall. The temperature difference between the two thermocouples is around $10^{\circ} \mathrm{C}$. After production, pyrochars were sieved to $2 \mathrm{~mm}$.

The two hydrochars were prepared as follows: $1.0 \mathrm{~L}$ of wet MW solution with $30 \%$ solids content was introduced in a Teflon recipient inside a Hastelloy autoclave supplied by Demede S.L. The autoclave has two thermocouples, one is inserted into the Teflon recipient in contact with the sample and another one is connected with the outer part of the Hastelloy wall. The temperature difference between the two thermocouples is around $20^{\circ} \mathrm{C}$. Samples were heated at 190 and $240{ }^{\circ} \mathrm{C}$ and the final temperature was maintained during $6 \mathrm{~h}$ under autogenous pressures, leading to HMW190 and HMW240 respectively. After cooling down to room temperature, the aqueous solutions were filtered and the hydrochars were dried at $90^{\circ} \mathrm{C}$ during $24 \mathrm{~h}$ and sieved to $2 \mathrm{~mm}$.

\subsection{Material characterization}

MW, pyrochars (BMW450 and BMW600) and hydrochars (HMW190 and HMW240) were characterized as follows:

Electrical conductivity (EC) and $\mathrm{pH}$ were determined in a $4 \mathrm{~g} \mathrm{~L}^{-1}$ aqueous sample solution, after $1 \mathrm{~h}$ of agitation, using a Crison micro-pH 2000 and a Crison 222 conductivimeter. Organic carbon $\left(\mathrm{C}_{\mathrm{oxi}}\right)$ was determined using the Walkley Black method, based on the oxidation of the organic carbon with dichromate [21]. Soluble organic carbon $\left(\mathrm{C}_{\mathrm{sol}}\right)$ was determined in a similar way to $\mathrm{C}_{\text {oxi }}$, after sample extraction using a 1:10 sample: water ratio and agitation during $1 \mathrm{~h}$ [21]. The extractable phosphorus $\left(\mathrm{P}_{\mathrm{olsen}}\right)$ was determined by the Olsen method using a Shimadzu UV-1203 spectrophotometer at a wavelength of $430 \mathrm{~nm}$ [22]. Cation exchange capacity (CEC) was determined using the method proposed by Ciesielski and Sterckeman [23] by means of Cohex extractant solution and determination of exchangeable cations using a Perkin Elmer Analyst 400 Atomic Absorption Spectrophotometer. Nitrogen isotherms and BET surface area $\left(\mathrm{S}_{\mathrm{BET}}\right)$ were determined using a Porosimetry System- ASAP 2020 -Micromeritics and Hg porosimetry was carried out using a Micromeritics AutoPore IV 9500 equipment. Carbon, hydrogen, nitrogen and sulphur contents were determined by dry combustion using a LECO CHNS 932 Analyzer. Oxygen was obtained by difference as $100 \%-(\% \mathrm{C}+\% \mathrm{H}+\% \mathrm{~N}+\% \mathrm{~S}+\% \mathrm{Ash})$. Atomic ratios $(\mathrm{H} / \mathrm{C}$ and $\mathrm{O} / \mathrm{C})$ were also determined. For proximate analysis, $\mathrm{N}_{2}$ adsorption and $\mathrm{Hg}$ porosimetry, all samples were used in powder after fine grinding below $100 \mu \mathrm{m}$. Representative samples were taken for analysis. The correlation coefficient obtained was highest than 0.999 for the BET and micropore area determinations.

Thermogravimetric analyses (TG and dTG) and differential thermal analysis (DTA) were carried out in a Thermogravimetric Analyzer TGA Labsys Setaram (Setaram Instruments). Twenty $\mathrm{mg}$ of sample were heated at $15^{\circ} \mathrm{C} \mathrm{min}^{-1}$ until $850^{\circ} \mathrm{C}$ in air atmosphere using a flow rate of $30 \mathrm{~mL} \mathrm{~min}^{-1}$. Thermogravimetric results (TG) were quantified as the weight loss of samples attributed to different temperature ranges: WL1 from 25 to $150^{\circ} \mathrm{C}$; WL2 from 200 to $400^{\circ} \mathrm{C}$ and WL3 from 400 to $600^{\circ} \mathrm{C}$ [10]. WL1 was related to water release from sample, whereas WL2 and WL3 corresponded to weight loss associated to organic matter combustion. It is established that the first peak (WL2) can be credited to the combustion of less humified organic matter, whilst the second one is related to more humified organic matter (WL3) [10,24]. The WL3/WL2 ratio, named thermostability index, has been previously identified as a reliable parameter for evaluating the level of stability of organic matter in pyrochars, composts or other organic wastes $[10,25]$. This index provides the relative amount of the thermally more stable fraction of organic matter with respect to the less stable one.

Carbon, hydrogen, nitrogen and sulphur contents were determined by dry combustion using a LECO CHNS 932 Analyzer. Oxygen was obtained by difference as $100 \%-(\% \mathrm{C}+\% \mathrm{H}+\% \mathrm{~N}+\% \mathrm{~S}+\% \mathrm{Ash})$. Atomic ratios $(\mathrm{H} / \mathrm{C}$ and $\mathrm{O} / \mathrm{C}$ ) were also determined.

The degree of humification was determined according to 
Zbytniewski and Buszewski [26]. One gram of each sample was weighted into a $250 \mathrm{~mL}$ polyethylene flask and extracted with $50 \mathrm{~mL}$ of $0.5 \mathrm{M} \mathrm{NaOH}$ and a shaking period of $2 \mathrm{~h}$. Absorption was measured at 280,472 and $664 \mathrm{~nm}$ using a UV-vis Shimadzu UV-1203. Absorption rates were calculated as follows: Q2/6 $=\mathrm{A} 280 / \mathrm{A} 664, \mathrm{Q} 4 / 6=\mathrm{A} 472 /$ $\mathrm{A} 664, \mathrm{Q} 2 / 4=\mathrm{A} 280 / \mathrm{A} 472$. Q2/6 represents the relationship between non-humified and strongly humified material; Q4/6 is called humification index. Q2/4 represents the proportion between lignins and other materials at the beginning of humification.

Analysis of samples by Fourier transform infrared spectrometry (FTIR) was performed using a spectrophotometer Bruker Vector 22.

For the determination of char stability, $\mathrm{CO}_{2}$ emissions during a laboratory incubation were measured. In each experiment, $10 \mathrm{~g}$ of dry samples were introduced in a $1 \mathrm{~L}$ glass vessel and the evolved $\mathrm{CO}_{2}$ was determined for 50 days at a temperature of $20^{\circ} \mathrm{C}$. $\mathrm{CO}_{2}$ emissions were measured at field capacity and this water content was maintained over the evaluation period. Evolved $\mathrm{CO}_{2}$ was trapped in $50 \mathrm{~mL}$ of a $1 \mathrm{M}$ $\mathrm{NaOH}$ solution. Titration of the trapped $\mathrm{CO}_{2}$ was performed using $1 \mathrm{M}$ $\mathrm{HCl}$ after the precipitation of carbonates with $\mathrm{BaCl}_{2}$. Triplicate $\mathrm{CO}_{2}$ measurements of each char were taken periodically and another three vessels without samples were used as blanks.

Finally, the germination test was performed using Lepidium sativum seeds and following the Zucconi phytotoxicity methodology $[27,28]$ Germination index (GI) was calculated and samples were classified as follows: GI values $<50 \%$ as highly phytotoxic; GI between $50-80 \%$ as moderately phytotoxic, GI $>80 \%$ as non phytotoxic and GI $>100 \%$ as phytostimulant $[27,28]$. Germination tests were performed in triplicate.

\subsection{Statistical analysis}

The statistical analysis of experimental results was performed using the Statgraphics Centurion XVI.I. software. Differences between means were tested using an analysis of variance (ANOVA) with means considered to be different when $p<0.05$, using Duncan's multiple range test.

\section{Results and discussion}

Table 1 summarized chemical and physical properties of MW, pyrochars and hydrochars. The $\mathrm{pH}$ values of pyrochars raised with increasing pyrolysis temperature. Similar results were found in previous studies by other authors [6,29]. Cely et al. [6] reported that the $\mathrm{pH}$ of chicken manure increased from 5.8 to 10.6 after pyrolysis at $500^{\circ} \mathrm{C}$ and that $\mathrm{pH}$ the of cattle manure shifted from 8.8 to 10.2 after pyrolysis at the same temperature. It is well-established that the $\mathrm{pH}$ increment with pyrolysis temperature is due to ash enrichment and polymerization/ condensation reactions resulting in the release of several acidic groups from char surface [29]. On the contrary, the two hydrochars showed a lower $\mathrm{pH}$ value than the initial $\mathrm{MW}$ and the two pyrochars. The $\mathrm{pH}$ value increased with HTC temperature. Liu et al. [30] have observed similar results. During HTC process reactions, some organic acids were produced and could be adsorbed on the hydrochar surface. Reza et al. [31] also reported that hydrochars produced at $200^{\circ} \mathrm{C}$ had lower $\mathrm{pH}$ values than hydrochars produced at $260^{\circ} \mathrm{C}$. Simple sugars and hemicellulose are degraded into organic acids that are later polymerized at low HTC temperatures, while lignin starts to degrade producing phenolic substances with only slightly acidic $\mathrm{pH}$ at high HTC temperatures. In addition, some alkaline compounds could dissolve in the aqueous phase, decreasing hydrochar $\mathrm{pH}[31,32]$.

The electrical conductivity (EC) is used to estimate the content of dissolved salts in samples. EC values for the two hydrochars were lower than the EC of MW indicating low content of soluble salts after HTC despite of higher ash concentration in chars. During HTC, some soluble salts could dissolve in the aqueous phase. The EC of the pyrochars was similar to the EC of the raw material, in spite of higher ash content. This result was in accordance to previous works that have shown that pyrolysis reduces the leaching of salts and trace metals [33].

Both, exchangeable Na and $\mathrm{K}$ content of feedstock, decreased after HTC. Reza et al. [31] found that a large proportion of pre-existing inorganic elements in the feedstock such as $\mathrm{Na}, \mathrm{K}$, Ca or $\mathrm{Mg}$ were removed with HTC. However, in our case, the exchangeable Ca content increased after HTC. The two pyrochars showed lower exchangeable Ca and $\mathrm{Na}$ content and similar $\mathrm{K}$ content compared to the feedstock.

Calvelo-Pereira et al. [34] established that organic carbon oxidized with potassium dichromate $\left(\mathrm{C}_{\mathrm{oxi}}\right)$ could be used to estimate the labile fraction of carbon in pyrochars and, consequently, the degree of biomass carbonization. $\mathrm{C}_{\text {oxi }}$ decreased significantly (Table 1) after pyrolysis of MW indicating the presence of more stable carbon structures in BMW450 and, particularly, in BMW600. However, the two hydrochars showed higher $\mathrm{C}_{\mathrm{oxi}}$ values than MW indicating that HTC treatment produced more labile carbon structures. Gascó et al. [13] described similar results for hydrochars prepared from pig manure. Comparing the $\mathrm{C}_{\text {oxi }}$ of both hydrochars, it can be observed that the $\mathrm{C}_{\text {oxi }}$ decreased with HTC temperature, probably due to the increment of polymerization/condensation reactions at higher HTC temperature. Other authors obtained similar results following chemical oxidation of organic carbon. For example, Han et al. [35] studied the oxidation of pyrochars and hydrochars with hydrogen peroxide and found that the oxidation resistance of hydrochars was similar to the oxidation resistance of pyrochar prepared at lower temperatures $\left(<450^{\circ} \mathrm{C}\right)$ and lower than oxidation resistance of pyrochar synthesized at higher temperatures $\left(600^{\circ} \mathrm{C}\right)$.

$\mathrm{C}_{\text {sol }}$ represents the $\mathrm{C}$ content that is soluble in water. The $\mathrm{C}_{\mathrm{sol}}$ decreased after both, pyrolysis and HTC treatments. However, the decrease was more noticeable for pyrochars, with values between $0.02 \%$ (BMW600) and $0.38 \%$ (BMW450), than for hydrochars, with values from $1.23 \%$ (HMW240) to $1.83 \%$ (HMW190). This result was related to the presence of less soluble carbon structures formed during HTC and, specially, during the pyrolysis process [36]. In the case of hydrochars, some soluble compounds of MW, or originated during HTC (for example organic acids), could dissolve in the aqueous phase during HTC process [37].

With respect to $\mathrm{P}_{\mathrm{Olsen}}$, its content decreased significantly after pyrolysis or HTC. However, previous work carried out by Gascó et al. [13] have shown that $\mathrm{P}_{\text {Olsen }}$ increased after HTC of pig manure. These contradictory results were indicative of the great influence of feedstock and HTC conditions on hydrochar properties. Therefore, a large amount of research is necessary in order to optimize the experimental conditions for the preparation of hydrochars, depending on their potential uses.

The CEC indicates the ability of materials to adsorb cations such as $\mathrm{Ca}^{2+}, \mathrm{Mg}^{2+}$ or $\mathrm{K}^{+}$. The $\mathrm{CEC}$ of $\mathrm{MW}\left(98.71 \mathrm{cmol}_{\mathrm{C}} \mathrm{kg}^{-1}\right.$ ) decreased significantly after pyrolysis or HTC treatments. The lowest value corresponded to hydrochar HMW240 $\left(18.88 \mathrm{cmol}_{\mathrm{c}} \mathrm{kg}^{-1}\right)$. The decrease in CEC could be due to a reduction in oxygenated functional groups [38] couple to a decrease in exchangeable $\mathrm{Na}$ and $\mathrm{K}$ in the particular case of the hydrochars [31] (Tables 1 and 2).

Table 2 shows elemental analysis, ash content and atomic ratios of MW, pyrochars and hydrochars. Pyrochars and hydrochars exhibited lower $\mathrm{H} / \mathrm{C}, \mathrm{O} / \mathrm{C}$ and $(\mathrm{N}+\mathrm{O}) / \mathrm{C}$ ratios than the raw material (MW). These ratios decreased with the temperature of both, pyrolysis or HTC, indicating an increase of aromaticity and a reduction of polarity as a function of temperature increment. This result was in agreement with previous works suggesting that pyrolysis or HTC can cause the removal of hydroxyls groups via dehydration, loss of carboxyl and carbonyl groups via decarboxylation, cleavage of ester and ether bonds via hydrolysis reactions and increasing aromatization via condensation reactions [39]. The aromaticity index $\mathrm{H} / \mathrm{C}$ (Table 2) is related to char resistance to both, chemical and microbial degradation [39]. Pyrochars' $\mathrm{H} / \mathrm{C}$ was lower than hydrochars' $\mathrm{H} / \mathrm{C}$, indicating the formation of more stable aromatic structures after pyrolysis than after HTC process. This result was in agreement with the $\mathrm{C}_{\text {oxi }}$ content after pyrolysis or HTC 
Table 1

Chemical and physical properties of manure waste, pyrochars and hydrochars.

\begin{tabular}{|c|c|c|c|c|c|}
\hline & MW & BMW450 & BMW600 & HMW190 & HMW240 \\
\hline $\mathrm{pH}$ & $9.20 \pm 0.06 c^{*}$ & $10.28 \pm 0.07 \mathrm{~d}$ & $10.32 \pm 0.07 \mathrm{~d}$ & $7.29 \pm 0.31 \mathrm{a}$ & $7.84 \pm 0.05 b$ \\
\hline $\mathrm{EG}\left(\mathrm{dS} \mathrm{m}^{-1}\right)$ & $0.62 \pm 0.01 \mathrm{c}$ & $0.60 \pm 0.00 \mathrm{c}$ & $0.60 \pm 0.03 c$ & $0.40 \pm 0.06 b$ & $0.26 \pm 0.02 \mathrm{a}$ \\
\hline $\mathrm{C}_{\mathrm{OX}}(\%)$ & $20.13 \pm 0.13 c$ & $11.28 \pm 0.07 b$ & $4.42 \pm 0.22 \mathrm{a}$ & $25.04 \pm 0.79 \mathrm{e}$ & $22.24 \pm 1.21 \mathrm{~d}$ \\
\hline $\mathrm{C}_{\mathrm{sol}}(\%)$ & $1.72 \pm 0.03 \mathrm{e}$ & $0.29 \pm 0.05 b$ & $0.02 \pm 0.00 \mathrm{a}$ & $1.41 \pm 0.03 \mathrm{~d}$ & $0.95 \pm 0.01 \mathrm{c}$ \\
\hline $\mathrm{CEC}\left(\mathrm{cmol}_{\mathrm{c}} \mathrm{kg}^{-1}\right)$ & $98.71 \pm 0.50 \mathrm{e}$ & $63.06 \pm 0.65 \mathrm{~d}$ & $50.65 \pm 1.27 \mathrm{c}$ & $39.23 \pm 0.90 \mathrm{~b}$ & $18.88 \pm 2.60 \mathrm{a}$ \\
\hline $\mathrm{P}_{\text {olsen }}\left(\mathrm{g} \mathrm{kg}^{-1}\right)$ & $4.70 \pm 0.01 \mathrm{e}$ & $1.52 \pm 0.03 c$ & $1.82 \pm 0.01 \mathrm{~d}$ & $0.98 \pm 0.02 b$ & $0.88 \pm 0.01 \mathrm{a}$ \\
\hline $\mathrm{Ca}\left(\mathrm{cmol}_{\mathrm{c}} \mathrm{kg}^{-1}\right)$ & $19.94 \pm 0.07 \mathrm{c}$ & $9.98 \pm 0.09 \mathrm{~b}$ & $6.05 \pm 0.31 \mathrm{a}$ & $35.06 \pm 2.07 \mathrm{e}$ & $26.55 \pm 0.52 \mathrm{~d}$ \\
\hline $\mathrm{Na}\left(\mathrm{cmol}_{\mathrm{c}} \mathrm{kg}^{-1}\right)$ & $26.49 \pm 0.13 e$ & $17.58 \pm 0.29 c$ & $21.21 \pm 0.28 \mathrm{~d}$ & $11.75 \pm 0.68 \mathrm{~b}$ & $7.67 \pm 0.16 a$ \\
\hline $\mathrm{K}\left(\mathrm{cmol}_{\mathrm{c}} \mathrm{kg}^{-1}\right)$ & $61.03 \pm 1.18 \mathrm{~d}$ & $50.6 \pm 0.84 c$ & $60.8 \pm 0.98 \mathrm{~d}$ & $27.57 \pm 0.56 b$ & $16.39 \pm 0.07 a$ \\
\hline
\end{tabular}

"Values followed by the same letter are not significantly different $(\mathrm{P}<0.05)$ using Duncan test.

Table 2

Elemental analysis and $\mathrm{H} / \mathrm{C}, \mathrm{O} / \mathrm{C}$ and $(\mathrm{N}+\mathrm{O}) / \mathrm{C}$ ratios of manure waste, pyrochars and hydrochars.

\begin{tabular}{|c|c|c|c|c|c|c|c|c|c|}
\hline \multirow[t]{2}{*}{ Samples } & \multicolumn{5}{|c|}{ Elemental analysis (wt\%) } & \multicolumn{2}{|c|}{ Atomic ratio } & \multirow[b]{2}{*}{$(\mathrm{N}+\mathrm{O}) / \mathrm{C}$} & \multirow[t]{2}{*}{ Ash $(w t \%)$} \\
\hline & $\mathrm{C}$ & $\mathrm{H}$ & $\mathrm{N}$ & $S$ & 0 & $\mathrm{H} / \mathrm{C}$ & $\mathrm{O} / \mathrm{C}$ & & \\
\hline MW & 20.37 & 3.11 & 1.94 & 0.32 & 33.91 & 1.83 & 1.25 & 1.33 & 40.36 \\
\hline BMW450 & 23.75 & 1.47 & 1.56 & 0.35 & 17.91 & 0.74 & 0.57 & 0.62 & 54.96 \\
\hline BMW600 & 23.41 & 1.08 & 1.45 & 0.37 & 6.41 & 0.55 & 0.21 & 0.26 & 67.29 \\
\hline HMW190 & 29.49 & 3.38 & 2.00 & 0.42 & 14.83 & 1.38 & 0.38 & 0.44 & 49.88 \\
\hline HMW240 & 29.93 & 3.10 & 2.00 & 0.42 & 10.76 & 1.24 & 0.27 & 0.33 & 53.80 \\
\hline
\end{tabular}

processes. Finally, the values of the $\mathrm{O} / \mathrm{C}$ and $(\mathrm{N}+\mathrm{O}) / \mathrm{C}$ ratios of the two hydrochars were between the values of BMW450 and BMW600. It is stablished that the presence of surface functional groups on char's surface can be related with the stability of chars, increasing with the reduction of the two indices [39]. Therefore, it is expected that pyrochar BMW600 will be more stable than hydrochars and pyrochar BMW450.

Table 3 shows $\mathrm{S}_{\mathrm{BET}}$, Vmicro, Vmeso and Vmacro. The surface area and porous structure provide potential habitats and are important factors in the char interaction with soil microorganisms and consequently, with their stability [40]. The two hydrochars showed higher surface areas than the pyrochars. In addition, the specific surface area and the Vmicro of pyrochars increased slightly with pyrolysis temperature. This increase in Vmicro was complemented by a decrease in the Vmeso and Vmacro at pyrolysis temperatures greater than $450^{\circ} \mathrm{C}$. Additionally, HTC increased significantly the specific surface area, Vmicro, Vmeso and Vmacro with respect to the feedstock, being the increment related with HTC temperature. Fig. 1 shows the $\mathrm{N}_{2}$ adsorption-desorption isotherms for manure waste, pyrochars and hydrochars. For all samples, the amount of $\mathrm{N}_{2}$ adsorbed is low due to the absence of activation processes during pyrochar or hydrochar preparation. However, adsorption capacities towards $\mathrm{N}_{2}$ were larger for both hydrochars than for biochars. According to the IUPAC classification, the three samples exhibit isotherms that could be classified as type IV.

Thermal analysis has been used for decades to characterize carbonaceous materials as they have the advantage to provide information about the chemical characteristics of the samples without the need for

Table 3

Surface area and porosity of manure waste, pyrochars and hydrochars.

\begin{tabular}{lllll}
\hline Sample & $\begin{array}{l}S_{\mathrm{BET}}\left(\mathrm{m}^{2}\right. \\
\left.\mathrm{g}^{-1}\right)\end{array}$ & $\begin{array}{l}\text { Vmicro } \\
\left(\mathrm{cm}^{3} \mathrm{~g}^{-1}\right)\end{array}$ & $\begin{array}{l}\text { Vmeso } \\
\left(\mathrm{cm}^{3} \mathrm{~g}^{-1}\right)\end{array}$ & $\begin{array}{l}\text { Vmacro } \\
\left(\mathrm{cm}^{3} \mathrm{~g}^{-1}\right)\end{array}$ \\
\hline MW & 1.1666 & 0.000177 & 0.02685 & 0.49131 \\
BMW450 & 4.8241 & 0.000191 & 0.04379 & 0.90560 \\
BMW600 & 4.6717 & 0.000372 & 0.03709 & 0.65347 \\
HMW190 & 14.2089 & 0.083643 & 0.08277 & 1.19482 \\
HMW240 & 14.9601 & 0.102282 & 0.13623 & 1.53749 \\
\hline
\end{tabular}

extraction steps $[13,24,25]$. Differences in the combustion behaviour of chars are indicative of contrasts in their composition [13,41]. Figs. 2 and 3 show the derivative thermogravimetric analysis (dTG) and differential thermal analysis (DTA) of MW, pyrochars and hydrochars.

Three stages could be differentiated during the combustion of samples. The initial mass loss from room temperature to $150^{\circ} \mathrm{C}$ was due to loss of moisture and volatilization of very light volatile materials (Stage I). However, the main differences between feedstock, pyrochars and hydrochars were observed from 200 to $650{ }^{\circ} \mathrm{C}$ when combustion of organic carbon takes place (Stage II) [42]. Two regions could be differentiated [41]: the first one, from 200 to $375^{\circ} \mathrm{C}$, is attributed to the decomposition/combustion of light compounds and carbohydrates such as cellulose or hemicellulose while the second one, from 375 to $600-650^{\circ} \mathrm{C}$, is related to the combustion of more stable structures with high molecular weight [43] in conjunction with combustion of refractory carbon.

dTG curves (Fig. 2) showed that the combustion peak, with a maximum at $280^{\circ} \mathrm{C}$ for $\mathrm{MW}$, became thinner when the temperature of HTC increased, and it was almost unnoticeable for pyrochars. This fact indicates that, during both thermal treatments, light compounds were decomposed or transformed during polymerization/condensation reactions. For pyrochars, the second combustion band was displaced to higher temperatures, indicating a higher carbonization at higher pyrolysis temperature. This result is related to the $\mathrm{C}_{\mathrm{OX}}$ content and the $\mathrm{H} / \mathrm{C}$ and $\mathrm{O} / \mathrm{C}$ ratios of pyrochars (Tables 1 and 2). Aromatic structures have a high thermal and chemical stability and suggests that pyrochars would be interesting materials for some applications, including carbon sequestration in soils or metallurgical purposes.

There are important differences between the dTG of hydrochars and the dTG of pyrochars and MW. Specifically, the second combustion band $\left(375-600^{\circ} \mathrm{C}\right)$ was displaced to lower temperatures in hydrochars, indicating that HTC produced less polymerized structures than pyrolysis, which mainly promotes carbonization of organic matter. This result was in agreement to the higher content of $\mathrm{C}_{\mathrm{ox}}$ and $\mathrm{H} / \mathrm{C}$ and $\mathrm{O} / \mathrm{C}$ atomic ratios, which indicate a greater presence of aliphatic groups in hydrochars compared to pyrochars. Finally, weight loss at temperatures between $700-850^{\circ} \mathrm{C}$ is related to carbonate decomposition (Stage III). Pyrochars showed a higher content of carbonates than manure, which 

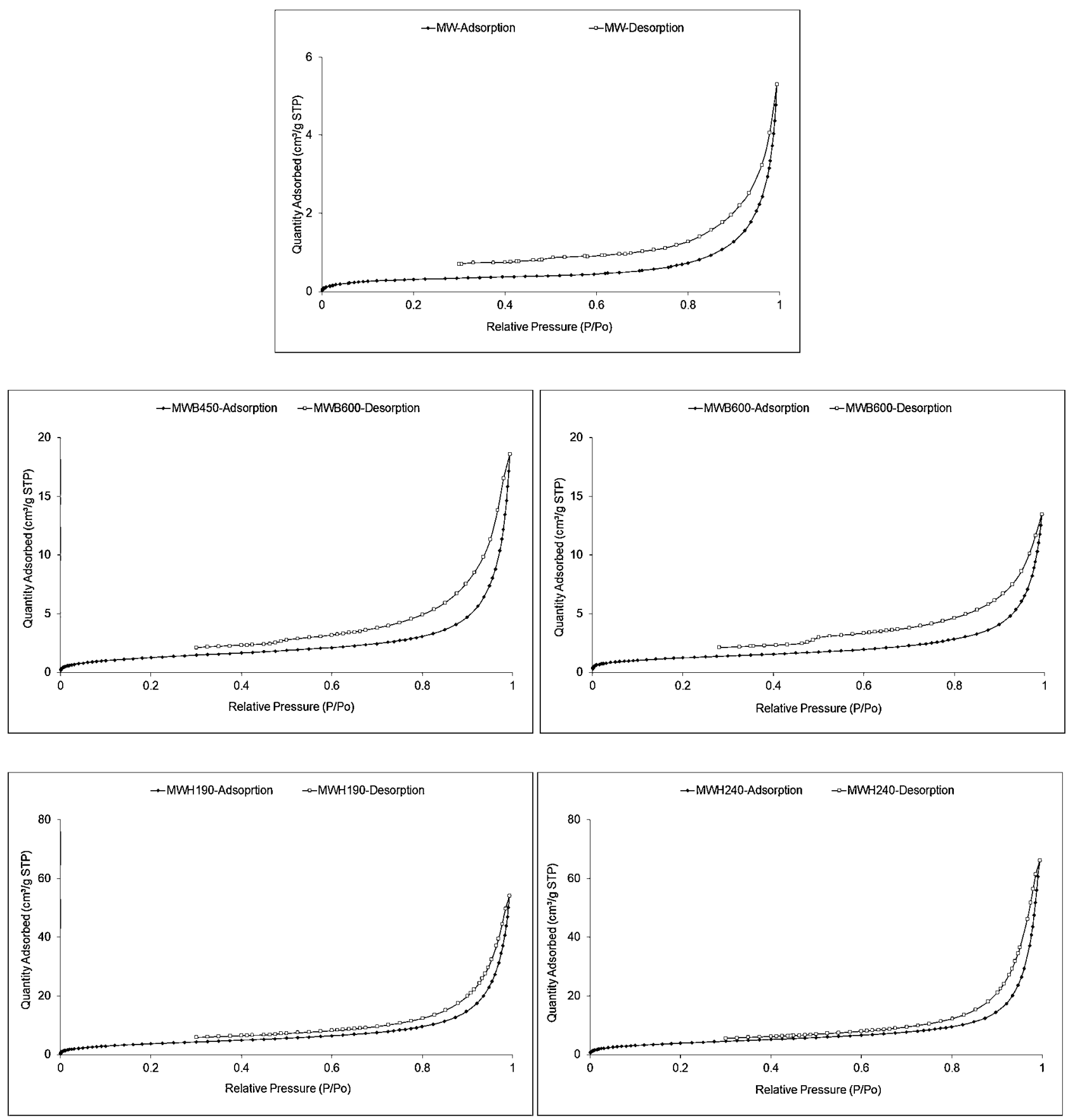

Fig. 1. $\mathrm{N}_{2}$ adsorption-desorption isotherms for waste, pyrochars and hydrochars.

was attributed to higher ash content, while the hydrochars' carbonate content, despite their higher ash content, seems to be lower than pyrochars. This fact can indicate that some carbonates were solubilized in the aqueous phase during the HTC process. Indeed, $\mathrm{CO}_{2}$ formation due to decarboxylation reactions taking place during HTC could promote the solubilisation of carbonates. Fig. 3 shows the DTA profiles of MW, pyrochars and hydrochars. DTA corroborates that combustion of pyrochars occurs at higher temperatures while combustion of hydrochars takes place at lower temperatures.

Additional information about the transformation of organic matter during pyrolysis or HTC can be provided by Q4/6, Q2/6 and Q2/4 ratios. The Q4/6 ratio followed the sequence: BMW600 < BMW450 $<$ HMW240 < HMW190 < MW. Q4/6 values were lower than 5 which is the typical value for humified materials [26]. Chars presented lower values than the raw material. The Q4/6 ratio indicates that HTC and, specially, pyrolysis treatment promote the humification of organic compounds and therefore, a high degree of aromatic condensation indicating a higher level of organic matter humification [13]. This fact is confirmed by the values of the thermostability index WL3/WL2 (Table 5), whose values follow the order BMW600 > BMW450 > HMW240 > HMW190 > MW, indicating that the temperature is a key factor on the thermal stability of organic matter after thermal 


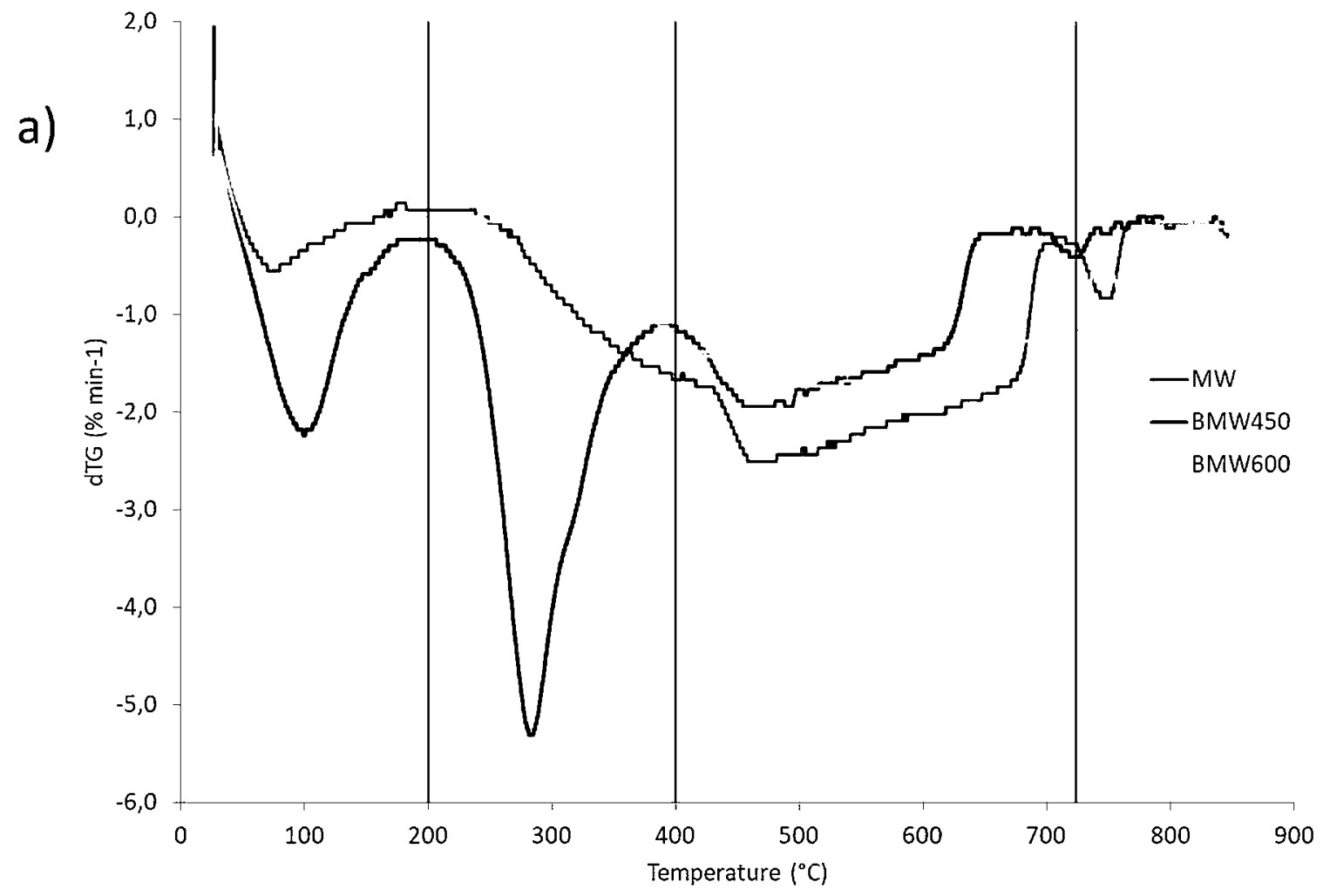

b)

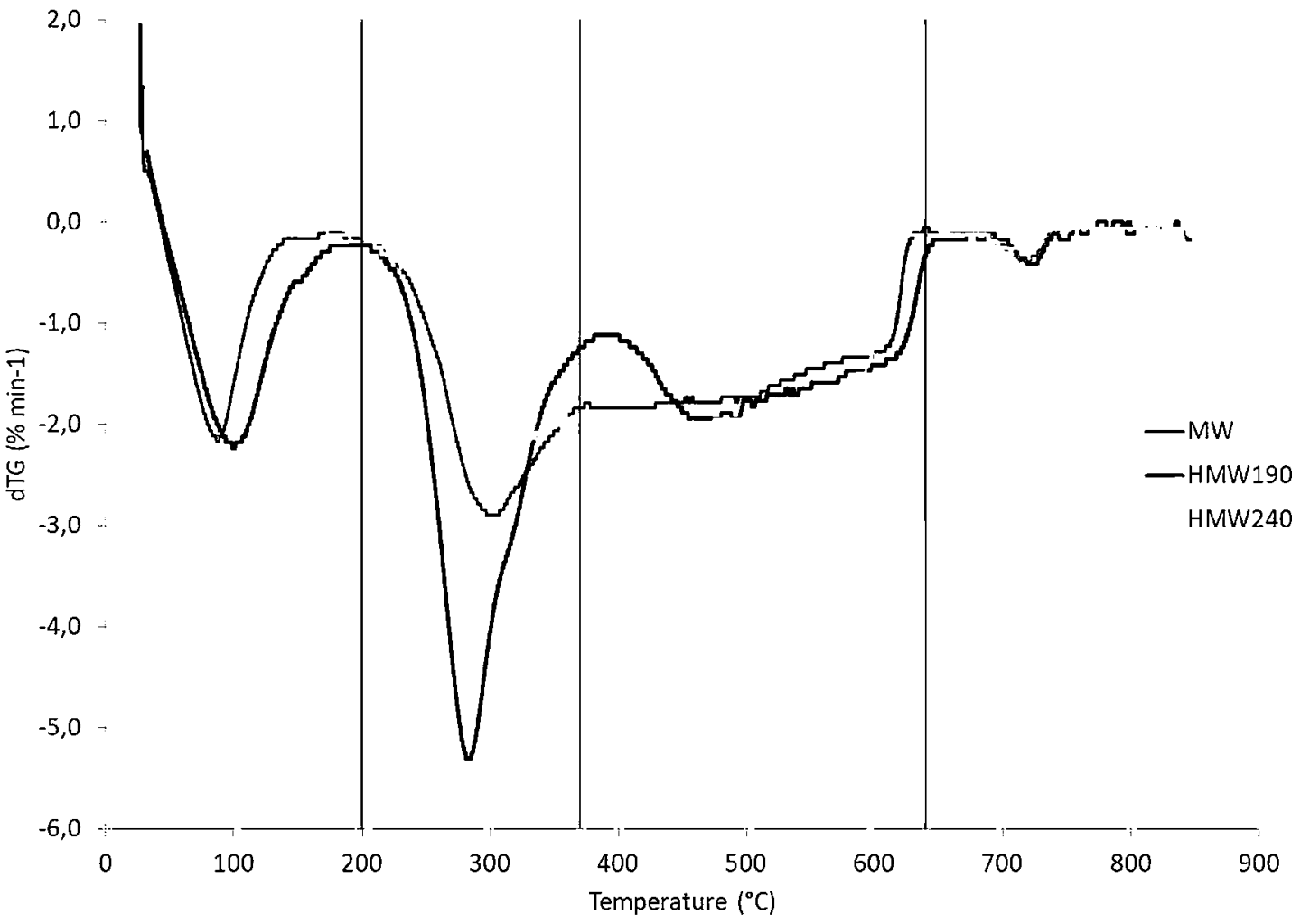

Fig. 2. dTG $\left(\% \mathrm{~min}^{-1}\right)$ curves for waste, pyrochars and hydrochars. 
a)

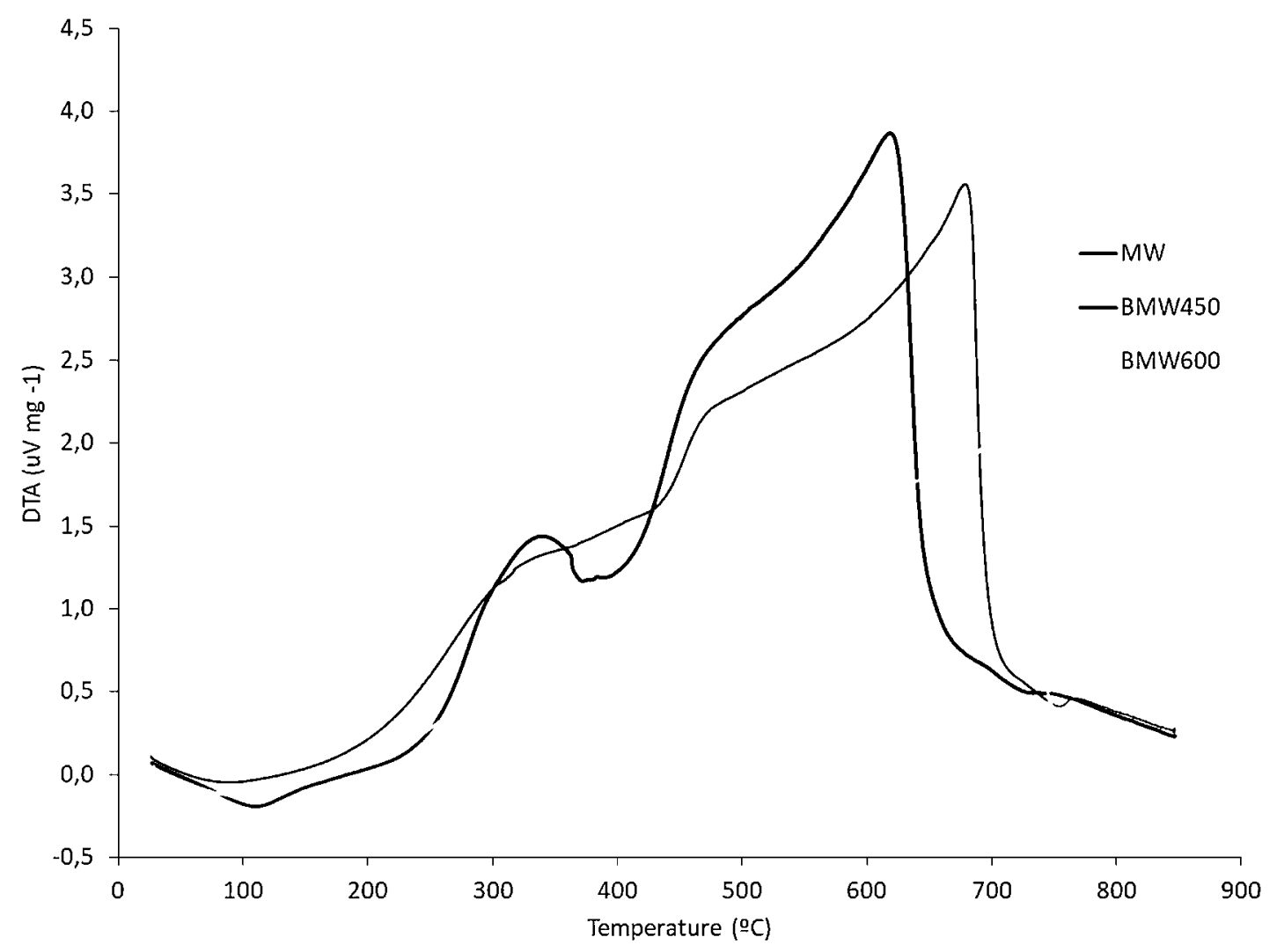

b)

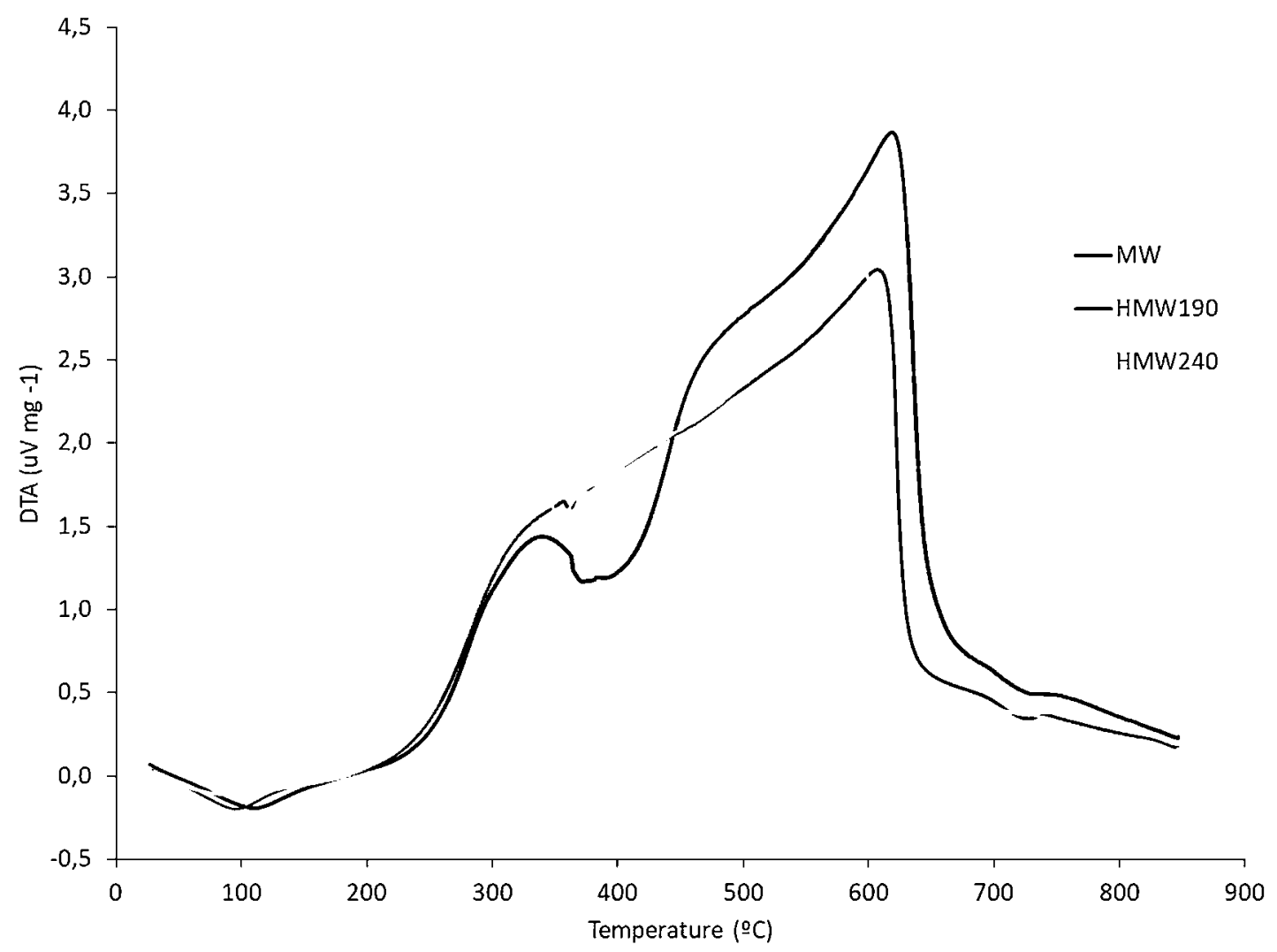

Fig. 3. DTA curves $\left(\mu \mathrm{mg}^{-1}\right)$ for waste, biochars and hydrochars. 


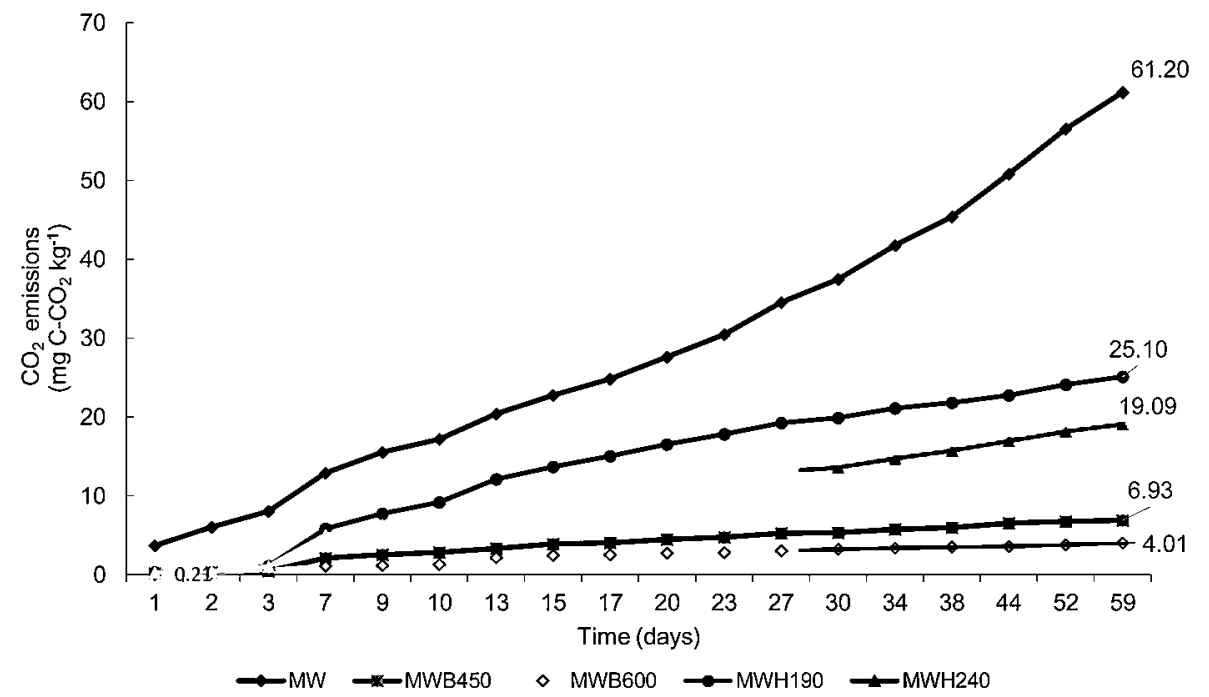

Fig. 4. Cumulative curve of $\mathrm{CO}_{2}$ emissions evolved during the incubation of waste, pyrochars and hydrochars.

Table 4

Absorbance ratios of $0.5 \mathrm{M} \mathrm{NaOH}$ solutions for samples.

\begin{tabular}{llll}
\hline Samples & Q4/6 & Q2/6 & Q2/4 \\
\hline MW & $4.83 \pm 0.09 \mathrm{e}^{*}$ & $0.95 \pm 0.01 \mathrm{a}$ & $0.20 \pm 0.01 \mathrm{a}$ \\
BMW450 & $2.88 \pm 0.14 \mathrm{~b}$ & $1.87 \pm 0.07 \mathrm{c}$ & $0.72 \pm 0.03 \mathrm{c}$ \\
BMW600 & $1.34 \pm 0.04 \mathrm{a}$ & $2.35 \pm 0.04 \mathrm{c}$ & $1.65 \pm 0.12 \mathrm{~d}$ \\
HMW190 & $4.09 \pm 0.08 \mathrm{~d}$ & $1.74 \pm 0.03 \mathrm{~b}$ & $0.42 \pm 0.00 \mathrm{~b}$ \\
HMW240 & $3.82 \pm 0.04 \mathrm{c}$ & $1.66 \pm 0.01 \mathrm{~b}$ & $0.42 \pm 0.01 \mathrm{~b}$ \\
\hline
\end{tabular}

*Values followed by the same letter are not significantly different $(\mathrm{P}<0.05)$ using Duncan test.

treatment. Q2/6 and Q2/4 ratios followed the order $\mathrm{MW}<$ HMW240 = HMW190 < BMW450 < BMW600 in accordance to Gascó et al. [25] who described also an increment of these ratios after the pyrolysis of biosolids at $500^{\circ} \mathrm{C}$.

Fig. 4 shows $\mathrm{CO}_{2}$ emissions of $\mathrm{MW}$, pyrochars and hydrochars after the incubation experiment ( 60 days). Evolved $\mathrm{CO}_{2}$ followed the order: $\mathrm{MW}>\mathrm{HMW} 190>\mathrm{HMW} 240>\mathrm{BMW} 450>$ BMW600. Indeed, pyrolysis reduced the percentage of evolved $\mathrm{CO}_{2}$ between $97.8-88.7 \%$ and the HTC treatment between $68.8-59.0 \%$, compared to MW. This decrease of $\mathrm{CO}_{2}$ emissions is related to the higher degree of organic matter humification and thermal stability after both, pyrolysis and HTC treatments, as mentioned above (Tables 4 and 5). These results are in agreement to previous works $[44,45]$, which described a reduction of $\mathrm{CO}_{2}$ emissions after pyrolysis of different organic wastes.

Finally, Fig. 5 shows the values of the germination index for the different materials. Germination index (GI) of MW, MWB450 and the two hydrochars (MWH190 and MWH240) were below 20\% indicating a high phytotoxicity. Nevertheless, pyrolysis at $600^{\circ} \mathrm{C}$ (MWB600) reduced the phytotoxicity with respect to the raw material although the value was lower than $80 \%$ indicating a moderate phytotoxicy $[27,28]$. The values measured for GI are lower than those obtained by other

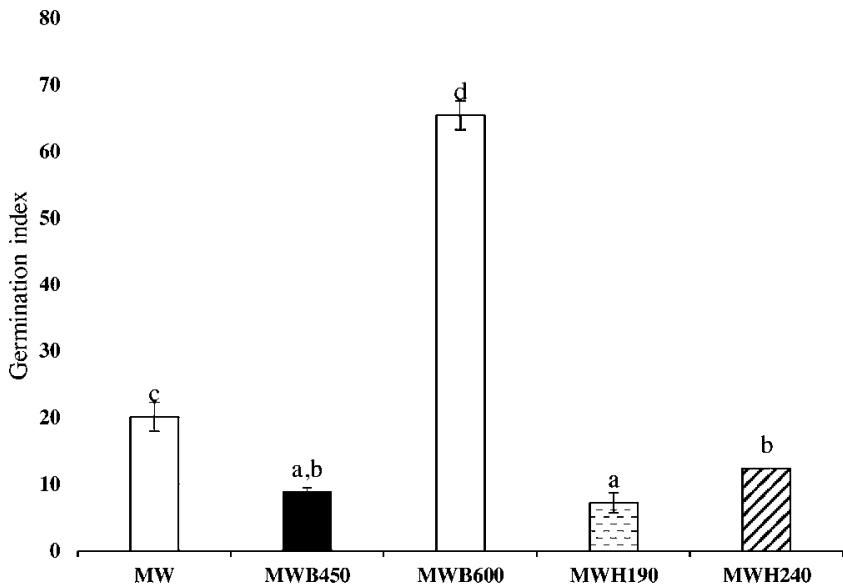

Fig. 5. Germination index for waste, pyrochars and hydrochars.

authors [46] indicating than these values are highly dependant on raw material, thermal treatment conditions and plant species.

In summary, the properties of chars determine their potential application for environmental purposes. For carbon sequestration, all chars reduced the $\mathrm{CO}_{2}$ emissions with respect to the raw material, particularly pyrochars MWB450 and MWB600. In addition, the chars have an adequate $\mathrm{pH}$, cation exchange capacity and nutrient content for their use in the remediation of contaminated acidic soils and for agricultural purposes. MWB600 was more suitable than other materials due to its lower phytotoxicity. The hydrochars could be used in soils and for other environmental purposes, including as growing media component or as water adsorbents, after thermal treatment for reducing the toxic compound content sorbed in hydrochars' surface [47].

Table 5

Thermogravimetric parameters of samples.

\begin{tabular}{|c|c|c|c|c|c|c|}
\hline Samples & WL1 & WL2 & WL3 & WL2/(WL2 + WL3) & WL3/(WL2 + WL3) & WL3/WL2 \\
\hline MW & 7.02 & 29.15 & 25.84 & 0.53 & 0.47 & 0.89 \\
\hline BMW450 & 0.14 & 9.48 & 40.17 & 0.19 & 0.81 & 4.24 \\
\hline BMW600 & 2.14 & 5.56 & 30.44 & 0.15 & 0.85 & 5.47 \\
\hline HMW190 & 5.19 & 23.21 & 24.23 & 0.49 & 0.51 & 1.04 \\
\hline HMW240 & 0.1 & 20.06 & 26.37 & 0.43 & 0.57 & 1.31 \\
\hline
\end{tabular}




\section{Conclusions}

The results show that pyrolysis produces chars with predominantly aromatic structures while HTC results in chars with a higher content in aliphatic structures. This fact is confirmed by the thermostability index, which followed the sequence BMW600 > BMW450 > HMW240> HMW190 > MW indicating that the temperature is a key factor on the organic matter thermal stability of rabbit manure after thermal treatment. In addition, HTC produced chars with more micro-, meso- and macro-porosity than pyrolysis. Finally, pyrolysis reduced $\mathrm{CO}_{2}$ emissions between $97.77-88.7 \%$ while HTC diminished these between $68.8-59.0 \%$, demonstrating that both treatments can be considered as carbon fixation technologies.

\section{Acknowledgement}

Authors wish to thank Spanish Ministerio de Economia $y$ Competitividad for economic support (CGL2014-58322-R).

\section{References}

[1] H. Foged, X. Flotats Ripoll, A. Bonmatí Blasi, J. Palatsi Civit, A. Magrí Aloy, K.M. Schelde, Inventory of manure processing activities in Europe, Technical Report No. I to the European Commission, Agro Business Park, Tjele, 2011.

[2] Z. He, P.H. Pagliari, H.M. Waldrip, Applied and environmental chemistry of animal manure: a review, Pedosphere 26 (2016) 779-816, https://doi.org/10.1016/ S1002-0160(15)60087-X

[3] R.M. Atiyeh, C.A. Edwards, S. Subler, J.D. Metzger, Pig manure vermicompost as a component of a horticultural bedding plant medium: effects on physicochemical properties and plant growth, Bioresour. Technol. 78 (2001) 11-20, https://doi.org/ 10.1016/S0960-8524(00)00172-3.

[4] M.V. Gil, M.T. Carballo, L.F. Calvo, Fertilization of maize with compost from cattle manure supplemented with additional mineral nutrients, Waste Manag. 28 (2008) 1432-1440, https://doi.org/10.1016/j.wasman.2007.05.009.

[5] C. Paredes, M.D. Pérez-Murcia, M.A. Bustamante, A. Pérez-Espinosa, E. Agulló, J. Moreno-Caselles, Valorization of Mediterranean livestock manures: composting of rabbit and goat manure and quality assessment of the compost obtained, Commun. Soil Sci. Plant Anal. 46 (2015) 248-255, https://doi.org/10.1080/ 00103624.2014 .989027

[6] P. Cely, G. Gascó, J. Paz-Ferreiro, A. Méndez, Agronomic properties of biochars from different manure wastes, J. Anal. Appl. Pyrolysis 111 (2015) 173-182, https://doi.org/10.1016/j.jaap.2014.11.014.

[7] B.M. Ghanim, W. Kwapinski, J.J. Leahy, Hydrothermal carbonisation of poultry litter: effects of initial $\mathrm{pH}$ on yields and chemical properties of hydrochars, Bioresour. Technol. 238 (2017) 78-85, https://doi.org/10.1016/j.biortech. 2017. 04.025 .

[8] M. Tripathi, J.N. Sahu, P. Ganesan, Effect of process parameters on production of biochar from biomass waste through pyrolysis: a review, Renew. Sustain. Energy Rev. 55 (2016) 467-481, https://doi.org/10.1016/j.rser.2015.10.122

[9] M. Hitzl, A. Corma, F. Pomares, M. Renz, The hydrothermal carbonization (HTC) plant as a decentral biorefinery for wet biomass, Catal. Today 257 (2015) 154-159, https://doi.org/10.1016/j.cattod.2014.09.024.

[10] A. Méndez, M. Terradillos, G. Gascó, Physicochemical and agronomic properties of biochar from sewage sludge pyrolysed at different temperatures, J. Anal. Appl. Pyrolysis 102 (2013) 124-130, https://doi.org/10.1016/j.jaap.2013.03.006.

[11] P. Wang, J. Zhang, Q. Shao, G. Wang, Physicochemical properties evolution of chars from palm kernel shell pyrolysis, J. Therm. Anal. Calorim. 133 (2018) 1271-1280, https://doi.org/10.1007/s10973-018-7185-z.

[12] T. Wang, Y. Zhai, Y. Zhu, C. Li, G. Zeng, A review of the hydrothermal carbonization of biomass waste for hydrochar formation: process conditions, fundamentals, and physicochemical properties, Renew. Sustain. Energy Rev. 90 (2018) 223-247, https://doi.org/10.1016/j.rser. 2018.03.071

[13] G. Gascó, J. Paz-Ferreiro, M.L. Álvarez, A. Saa, A. Méndez, Biochars and hydrochars prepared by pyrolysis and hydrothermal carbonisation of pig manure, Waste Manage. 79 (2018) 395-403, https://doi.org/10.1016/j.wasman.2018.08.015.

[14] G. Gascó, J. Paz-Ferreiro, P. Cely, C. Plaza, A. Méndez, Influence of pig manure and its biochar on soil CO2 emissions and soil enzymes, Ecol. Eng. 95 (2016) 19-24, https://doi.org/10.1016/j.ecoleng.2016.06.039.

[15] W. Song, M. Guo, Quality variations of poultry litter biochar generated at different pyrolysis temperatures, J. Anal. Appl. Pyrolysis 94 (2012) 138-145, https://doi. oro/10.1016/j.jaap. 2011.11.018.

[16] F. Fornes, R.M. Belda, A. Lidón, Analysis of two biochars and one hydrochar from different feedstock: focus set on environmental, nutritional and horticultural considerations, J. Clean. Prod. 86 (2015) 40-48, https://doi.org/10.1016/j.jclepro. 2014.08.057.

[17] S. Schimmelpfennig, B. Glaser, One step forward toward characterization: some important material properties to distinguish biochars, J. Environ. Qual. 41 (2012) 1001-1013, https://doi.org/10.2134/jeq2011.0146.

[18] M. Gronwald, C. Vos, M. Helfrich, A. Don, Stability of pyrochar and hydrochar in agricultural soil - a new field incubation method, Geoderma 284 (2016) 85-92, https://doi.org/10.1016/j.geoderma.2016.08.019.

[19] D. Busch, A. Stark, C.I. Kammann, B. Glaser, Genotoxic and phytotoxic risk assessment of fresh and treated hydrochar from hydrothermal carbonization compared to biochar from pyrolysis, Ecotoxicol. Environ. Saf. 97 (2013) 59-66, https:// doi.org/10.1016/j.ecoenv.2013.07.003.

[20] I. Bargmann, M.C. Rillig, W. Buss, A. Kruse, M. Kuecke, Hydrochar and biochar effects on germination of spring barley, J. Agron. Crop Sci. 199 (2013) 360-373, https://doi.org/10.1111/jac.12024.

[21] D.W. Nelson, L.E. Sommers, Total carbon, organic carbon and organic matter, in: D.L. Sparks (Ed.), Methods of Soil Analysis. Part 3. Chemical Methods, SSSA, Madison, 1996, pp. 961-1010.

[22] F.S. Watanabe, S.R. Olsen, Test of ascorbic acid method for determining phosphorus in water and $\mathrm{NaHCO}_{3}$ extracts from Soil, Soil Sci. Soc. Am. J. 29 (1965) 677-678, https://doi.org/10.2136/sssaj1965.03615995002900060025x.

[23] H. Ciesielski, T. Sterckeman, M. Santerne, J.P. Willery, Determination of cation exchange capacity and exchangeable cations in soils by means of cobalt hexamine trichloride Effects of experimental conditions, Agronomie 17 (1997) 1-7, https:// doi.org/10.1051/agro:19970101.

[24] G. Gascó, C.G. Blanco, F. Guerrero, A. Méndez, The influence of organic matter on sewage sludge pyrolysis, J. Anal. Appl. Pyrolysis 74 (2005) 413-420, https://doi. org/10.4324/9780203824184

[25] G. Gascó, J. Paz-Ferreiro, A. Méndez, Thermal analysis of soil amended with sewage sludge and biochar from sewage sludge pyrolysis, J. Therm. Anal. Calorim. 108 (2012) 769-775, https://doi.org/10.1007/s10973-011-2116-2.

[26] R. Zbytniewski, B. Buszewski, Characterization of natural organic matter (NOM) derived from sewage sludge compost. Part 1: chemical and spectroscopic properties, Bioresour. Technol. 96 (2005) 471-478, https://doi.org/10.1016/j. biortech. 2004 . 05.018.

[27] F. Zucconi, A. Monaco, M. Forte, M. de. Bertoldi, Phytotoxins during the stabilization of organic matter, in: J.K.R. Gasser (Ed.), Composting of Agricultural and Other Wastes, Elsevier Applied Science Publication, New York, 1985, pp. 73-86.

[28] E.R. Emino, P.R. Warman, Biological assay for compost quality, Compost Sci. Util. 12 (2004) 342-348, https://doi.org/10.1080/1065657X.2004.10702203.

[29] M.K. Hossain, V. Strezov, K.Y. Chan, A. Ziolkowski, P.F. Nelson, Influence of pyrolysis temperature on production and nutrient properties of wastewater sludge biochar, J. Environ. Manage. 92 (2011) 223-228, https://doi.org/10.1016/j. jenvman.2010.09.008.

[30] Y. Liu, S. Yao, Y. Wang, H. Lu, S.K. Brar, S. Yang, Bio- and hydrochars from rice straw and pig manure: inter-comparison, Bioresour. Technol. 235 (2017) 332-337, https://doi.org/10.1016/j.biortech.2017.03.103.

[31] M.T. Reza, J.G. Lynam, M.H. Uddin, C.J. Coronella, Hydrothermal carbonization: fate of inorganics, Biomass Bioenergy 49 (2013) 86-94, https://doi.org/10.1016/j. biombioe.2012.12.004.

[32] H.S. Kambo, A. Dutta, A comparative review of biochar and hydrochar in terms of production, physico-chemical properties and applications, Renew. Sustain. Energy Rev. 45 (2015) 359-378, https://doi.org/10.1016/j.rser.2015.01.050.

[33] I.H. Hwang, Y. Ouchi, T. Matsuto, Characteristics of leachate from pyrolysis residue of sewage sludge, Chemosphere 68 (2007) 1913-1919, https://doi.org/10.1016/j. chemosphere. 2007.02.060.

[34] R. Calvelo Pereira, J. Kaal, M. Camps Arbestain, R. Pardo Lorenzo, W. Aitkenhead, M. Hedley, F. Macías, J. Hindmarsh, J.A. Maciá-Agulló, Contribution to characterisation of biochar to estimate the labile fraction of carbon, Org. Geochem. 42 (2011) 1331-1342, https://doi.org/10.1016/j.orggeochem.2011.09.002.

[35] L. Han, K.S. Ro, Y. Wang, K. Sun, H. Sun, J.A. Libra, B. Xing, Oxidation resistance of biochars as a function of feedstock and pyrolysis condition, Sci. Total Environ. 616-617 (2017) 335-344, https://doi.org/10.1016/j.scitotenv.2017.11.014.

[36] S. Kang, X. Li, J. Fan, J. Chang, Characterization of hydrochars produced by hy drothermal carbonization of lignin, cellulose, d-xylose, and wood meal, Ind. Eng. Chem. Res. 51 (2012) 9023-9031, https://doi.org/10.1021/ie300565d.

[37] C. Song, S. Shan, K. Müller, S. Wu, N.K. Niazi, S. Xu, Y. Shen, J. Rinklebe, D. Liu, H. Wang, Characterization of pig manure-derived hydrochars for their potential application as fertilizer, Environ. Sci. Pollut. Res. (2017) 1-8, https://doi.org/10. 1007/s11356-017-0301-y.

[38] C.A. Takaya, L.A. Fletcher, S. Singh, K.U. Anyikude, A.B. Ross, Phosphate and ammonium sorption capacity of biochar and hydrochar from different wastes, Chemosphere 145 (2016) 518-527, https://doi.org/10.1016/j.chemosphere. 2015. 11.052.

[39] K. Crombie, O. Mašek, S.P. Sohi, P. Brownsort, A. Cross, The effect of pyrolysis conditions on biochar stability as determined by three methods, GCB Bioenergy 5 (2013) 122-131, https://doi.org/10.1111/gcbb.12030.

[40] N.M. Jaafar, P.L. Clode, L. K. Abbott, Soil microbial responses to biochars varying in particle size, surface and pore properties, Pedosphere 25 (5) (2015), https://doi. org $/ 10.1016 / 81002-0160(15) 30058-8$.

[41] M.T. Dell'Abate, A. Benedetti, P. Sequi, Thermal methods of organic matter maturation monitoring during a composting process, J. Therm. Anal. Calorim. 61 (2000) 389-396, https://doi.org/10.1023/A:1010157115211.

[42] J. Kumpiene, R. Robinson, E. Brännvall, D. Nordmark, H. Bjurström, L. Andreas, A. Lagerkvist, H. Ecke, Carbon speciation in ash, residual waste and contaminated soil by thermal and chemical analyses, Waste Manag. 31 (2011) 18-25, https://doi. org/10.1016/j.wasman.2010.06.011.

[43] M. Pietro, C. Paola, Thermal analysis for the evaluation of the organic matter evolution during municipal solid waste aerobic composting process, Thermochim. Acta 413 (2004) 209-214, https://doi.org/10.1016/j.tca.2003.09.026.

[44] A. Méndez, A.M. Tarquis, A. Saa-Requejo, F. Guerrero, G. Gascó, Influence of pyrolysis temperature on composted sewage sludge biochar priming effect in a loamy 
soil, Chemosphere 93 (2013) 668-676, https://doi.org/10.1016/j.chemosphere. 2013.06 .004$.

[45] I. Benavente, G. Gascó, C. Plaza, J. Paz-Ferreiro, A. Méndez, Choice of pyrolysis parameters for urban wastes affects soil enzymes and plant germination in a Mediterranean soil, Sci. Total Environ. 634 (2018) 1308-1314, https://doi.org/10. 1016/j.scitotenv.2018.04.120.

[46] E. Cárdenas-Aguiar, G. Gascó, J. Paz-Ferreiro, A. Méndez, The effect of biochar and compost from urban organic waste on plant biomass and properties of an artificially copper polluted soil, Int. Biodeterior. Biodegrad. 124 (2017) 223-232, https://doi. org/10.1016/j.ibiod.2017.05.014.

[47] M. Hitzl, A. Mendez, M. Owsianiak, M. Renz, Making hydrochar suitable for agricultural soil: a thermal treatment to remove organic phytotoxic compounds, J

Environ. Chem. Eng. 6 (2018) 7029-7034, https://doi.org/10.1016/j.jece.2018.10. 064. 